\title{
Anticoagulant therapy in patients with atypical COVID-19 pneumonia
}

\author{
Ravshan Aliyevich IBADOV1', Gulchekhra Shakhobovna KHAMRAEVA², Sardor Khamdamovich IBRAGIMOV ${ }^{1} \bowtie$ \\ ${ }^{1}$ Republican Specialized Scientific and Practical Medical Center of Surgery Named after Academician V. Vakhidov, Tashkent, Republic of Uzbekistan \\ ${ }^{2}$ Center for the Development of Professional Qualifications of Medical Workers, Tashkent, Republic of Uzbekistan \\ Corresponding author's Email: dr.sardor.ibragimov@gmail.com; (DORCiD: 0000-0003-2876-411X
}

\section{ABSTRACT}

Aim. In a comparative aspect, this article aimed to evaluate the effectiveness of optimized intensive care protocols for severe and extremely severe COVID-19. Methods. During the study period, 4922 patients were treated in the intensive care units of the Republican Specialized Multidisciplinary Infectious Diseases Hospital (678 in the comparison group and 4244 in the main group). The developed protocol of anticoagulant therapy was applied to all patients in the main group. Results. There was an improvement in prothrombin time from $12.0 \pm 0.4$ to $13.6 \pm 0.3 \mathrm{sec}(\mathrm{P}<0.05)$ on day 3 , from $14.7 \pm 0.4$ to $16.2 \pm 0.3 \mathrm{sec}(\mathrm{P}<0.05)$ on day 10 , clotting time from $3.1 \pm 0.1$ to $3.3 \pm 0.1 \mathrm{~min}(\mathrm{P}<0.05)$ and from $3.7 \pm 0.1$ to $4.5 \pm 0.1 \mathrm{~min}$, respectively, and fibrinogen from $4.6 \pm 0.2$ to $4.2 \pm 0.1 \mathrm{~g} / \mathrm{l}(\mathrm{P}<0.05)$ and from $4.0 \pm 0.1$ to $3.4 \pm 0.1$ $\mathrm{g} / \mathrm{l}(\mathrm{P}<0.05)$, a decrease in the frequency of fatal thromboembolic complications from $25.1 \%$ to $16.6 \%(\mathrm{P}<0.001)$. Conclusion. The introduction of optimized tactics for anticoagulant therapy in patients with severe and extremely severe COVID-19 course made it possible to accelerate the dynamics of prothrombin time, fibrinogen, and blood clotting time, which ensured a decrease in the likelihood of developing fatal thromboembolic complications in the intensive care unit.

\section{Original Article}

PII: S225199392100005-11

Rec. 24 March 2021

Rev. 15 May 2021

Acc. 25 May 2021

\section{Keywords}

COVID-19,

Anticoagulant therapy,

Respiratory therapy,

Patients

\section{INTRODUCTION}

The COVID-19 pandemic has led not only to the overload of healthcare systems, but also created numerous challenges and complex tasks in understanding the pathogenesis of various manifestations of COVID-19, the solution of which is of paramount importance in the development of diagnostic and treatment algorithms [1-3]. Special attention among scientists is paid to the study of various mechanisms of thrombus formation, hematological aspects of the disease, and the need for anticoagulant prophylaxis in patients with COVID-19, including patients with pre-existing bleeding disorders $[4,5]$.

In order to improve survival rates, researchers are looking for definitive treatments and tactics for the treatment of COVID-19. Clinical data on the effectiveness of currently used pharmacological therapies remain scanty. In the context of specialized centers, the search for innovative approaches to the treatment of COVID-19 remains crucial.

Literature data indicate that the main causes of mortality in COVID-19 are common intravascular coagulopathy of the pulmonary vascular system, arterial and venous thromboembolism, disseminated intravascular coagulation syndrome, secondary hemophagocytic lymphohistiocytosis, and multiple organ failure syndromes. However, the optimal thromboprophylaxis regimen for COVID-19 is still unknown [6].

In accordance with most guidelines for the management of COVID-19, all hospitalized patients should be closely monitored for thrombotic events. However, there is currently insufficient evidence to define "high risk" and specific thresholds for individual factors, while, there is a lot of evidence indicating a higher tendency for thrombotic events in acute respiratory distress syndrome induced by COVID19 compared to respiratory failure caused by infections not associated with SARS-CoV-2 [7].

This article discusses the current understanding of the potential mechanisms underlying coagulopathy associated with COVID-19 and the results of anticoagulant therapy according to the developed national intensive care protocol for severe and extremely severe cases of COVID-19. 
The work is based on the analysis of the experience of treating patients with COVID-19 in the Republican Specialized Multidisciplinary Infectious Diseases Hospital. For an objective assessment of the activities of the organized system for the provision of qualified medical care, the analysis of the results was carried out for two time periods: the first period from the opening of the clinic on July 09, 2020, to August 15, and the second period from August 16, 2020, to December 31, 2020. In total, during the indicated periods, 678 patients in the comparison group and 4244 patients in the main group were treated in the intensive care units. No intergroup difference was noted for this indicator. Males slightly prevailed in each of the compared groups, 52.9\% of men were in the comparison group and $52.8 \%$ in the main group, respectively, and women were $47.1 \%$ and $47.2 \%$. In the age aspect, both in the comparison and main groups, the largest number of patients were admitted to the older age group 50-59 and 60-69 years old, so that in the comparison group (24.6\% and $20.4 \%$ ) and in the main group (24.4\% and $23.2 \%)$, respectively.

When patients were distributed according to the volume of lung damage, it was noted that up to $20 \%$ of lung tissue damage was diagnosed in $9.6 \%$ of patients from the comparison group and in $5.1 \%$ from the main group; up to $50 \%$ of lung tissue damage was diagnosed in $63.2 \%$ of patients from the comparison group and in $59.5 \%$ from the main group; up to $70 \%$ of lung tissue damage was diagnosed in $18.2 \%$ of the comparison group and in $24.3 \%$ from the main group; $>70 \%-8.9 \%$ of lung tissue damage was diagnosed from the comparison group and $11.2 \%$ from the main group.

In $40.4 \%$ of cases, the patients were on spontaneous breathing from the comparison group while it was $24.0 \%$ of cases from the main group. In addition, $4.8 \%$ of patients from the comparison group, and $1.3 \%$ of the main group were required to transfer to invasive mechanical ventilation. Non-invasive oxygenation was required in $54.7 \%$ of patients from the comparison group and $74.7 \%$ of patients from the main group.

With a confirmed laboratory method, $32.9 \%$ and $40.5 \%$ of patients from the comparison and main groups were respectively hospitalized, while $67.1 \%$ and $59.5 \%$ from both comparison and main groups were respectively hospitalized with the signs of COVID-19 pneumonia.

The developed protocol of anticoagulant therapy was applied to all patients in the study group. From the moment of admission to the hospital, Enoxaparin was prescribed at a dose of $160 \mathrm{mg}$ per day, divided into 2 doses. A day later, in cases where the control of the blood coagulation system showed that the clotting time (CT) was less than 4 minutes, the prothrombin time (PT) was less than 12 seconds, Clopidogrel (an antiplatelet medication) was additionally prescribed at a dose of $150 \mathrm{mg}$ and Acetylsalicylic acid at a dose of $100 \mathrm{mg}$ per day. If the target values of PT (more than 16 seconds) and BCT (more than 6 minutes) were not achieved, Heparin (anticoagulant) was administered intravenously at a dose of $1000 \mathrm{U} / \mathrm{h}$.

\section{Ethical approval}

The review board and ethics committee of Republican Specialized Scientific and Practical Medical Center for Surgery named after academician V.Vakhidov approved the study protocol and informed consents were taken from all the participants.

\section{Statistical analysis}

The studied groups data has been compared with software STATISTICA 13.3 (StatSoft.Inc). Data are shown as mean $(\mathrm{M} \pm \mathrm{m})$ values and comparisons were made using an unpaired $t$-test. Medians and interquartile range (IQR) are for skewed data, and comparisons were made using the Mann-Whitney $U$ test, $\mathrm{p}<0.05$ was considered significant.

\section{RESULTS AND DISCUSSION}

Analysis of the effectiveness of hyper-coagulation therapy (the main component of the proposed treatment tactics) showed that the dynamics of PT change depended on the initial severity of the condition. In the study groups upon admission of patients, the mean values of this indicator were comparable without a statistical difference for each of the subgroups of the severity of the disease. On the $7^{\text {th }}$ day from beginning of treatment, it could be noted that the average PT for moderate severity, was $14.2 \pm 0.5 \mathrm{sec}$. in the comparison group, and $15.6 \pm 0.4 \mathrm{sec}$. in the main group, while with severe form it was $13.6 \pm 0.4 \mathrm{sec}$. and $15.4 \pm 0.4$ sec., respectively, and in the extremely severe course of the disease the values were $11.4 \pm 0.4 \mathrm{sec}$. and $14.9 \pm 0.3 \mathrm{sec}$., respectively. Therefore, already on the $10^{\text {th }}$ day of being in the intensive care unit of patients in the main group, PT was in the range of 
the upper norm, amounting to $16.8 \pm 0.3 \mathrm{sec}$. for medium severity, $16.5 \pm 0.3 \mathrm{sec}$. for severe form, and $15.3 \pm 0.3 \mathrm{sec}$. with an extremely severe form of the disease.

In Figure 1 it can be seen that the analysis of the comparative dynamics of average PT values revealed an intergroup statistically significant difference $(\mathrm{t}=2.82-3.16$; $\mathrm{P}<0.05)$ and better indicators in the main group of patients at all stages of therapy (Figure 1).

With regard to the dynamics of $\mathrm{BCT}$, it could be noted that in the study groups upon admission of patients, the mean values of this indicator were comparable without a statistical difference for each of the subgroups of the severity of the disease. In the comparison group, within 14 days from the start of therapy, it could be noted that the BCT in patients with moderate severity varied from $3.1 \pm 0.08 \mathrm{~min}$. up to $4.6 \pm 0.3 \mathrm{~min}$. In the main group of patients, this indicator ranged from $3.0 \pm 0.07 \mathrm{~min}$. up to $5.2 \pm 0.2 \mathrm{~min}$. with a statistically significant difference only on the $7^{\text {th }}$ and $10^{\text {th }}$ days $(\mathrm{P}<0.05)$. For the severe form of the disease, the average $\mathrm{CT}$ ranged from $2.7 \pm 0.06 \mathrm{~min}$. up to $4.1 \pm 0.2 \mathrm{~min}$. in the comparison group, and $2.6 \pm 0.1 \mathrm{~min}$. up to $4.8 \pm 0.1 \mathrm{minutes}$ in the main group, while in an extremely severe course of the disease the average CT was from $2.5 \pm 0.05$ minutes to 3.7 \pm 0.1 minutes in the comparison group and $2.4 \pm 0.08$ up to $4.4 \pm 0.2$ minutes in the main group.

Thus, against the background of the proposed treatment tactics, it was possible to increase the CT with a statistically significant difference in severe and extremely severe forms of COVID-19 in the presence of concomitant pathologies and the use of aggressive methods of ventilation.

Analyzing the comparative dynamics of the mean CT indices showed an intergroup statistically significant difference was revealed $(\mathrm{t}=2.56-4.38 ; \mathrm{P}<0.05)$ and better indices in the main group of patients at all stages of therapy (Figure 2).

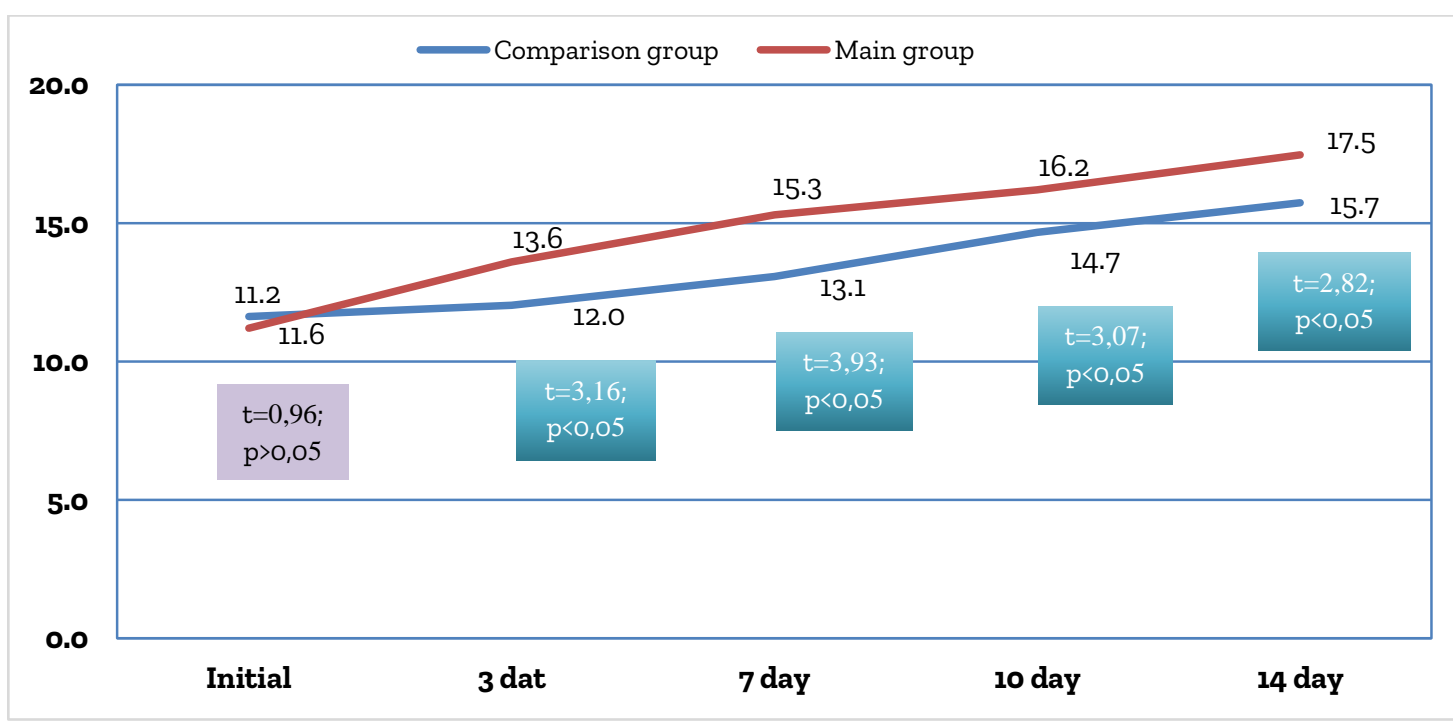

Figure 1. Comparative dynamics of prothrombin time (sec).

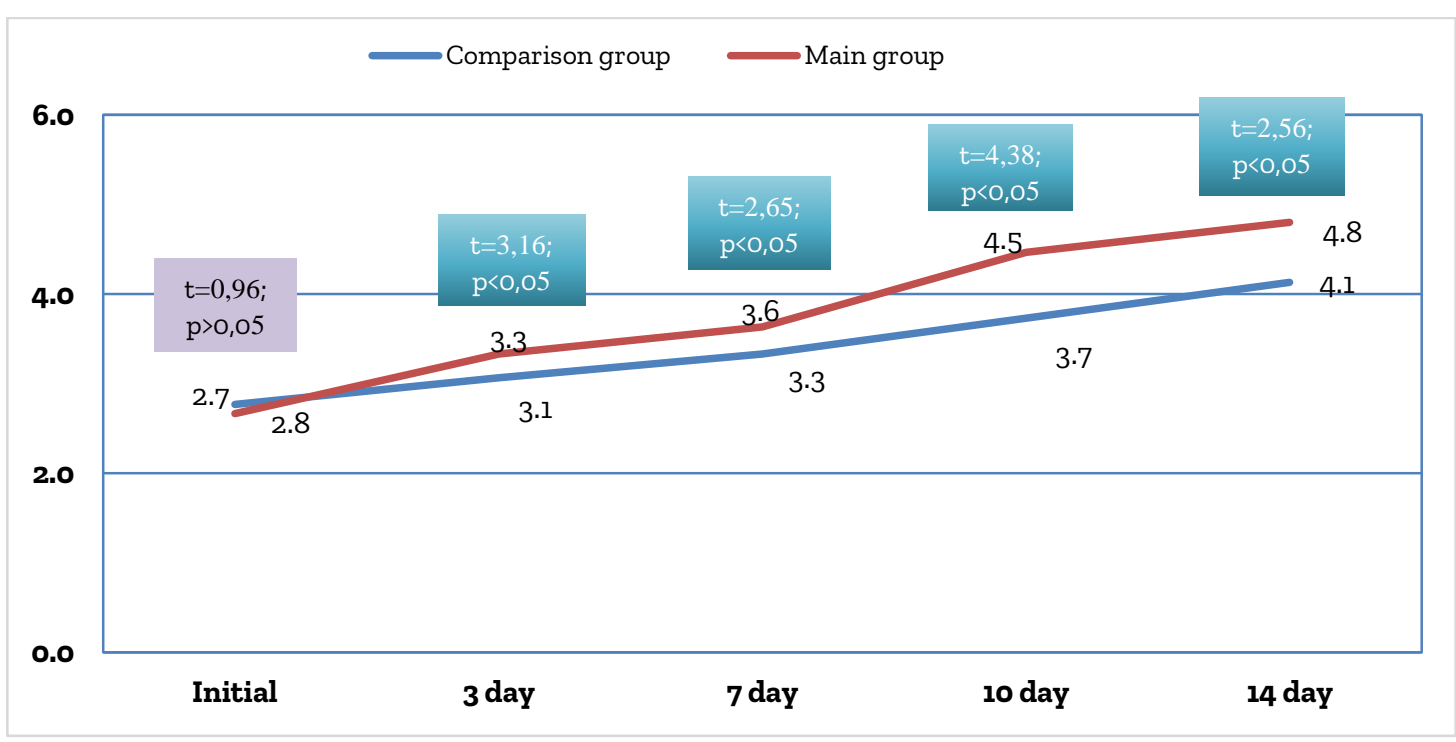

Figure 2. Comparative dynamics of the blood clotting time (min). 
In addition, the dynamics of serum fibrinogen were studied as an assessment criterion for the effectiveness of anticoagulant therapy. There was also some relatively better positive dynamics against the background of the proposed algorithm with a statistically significant difference at all stages of treatment in cohorts with severe and extremely severe COVID-19, and with moderate severity, the intergroup difference was significant only on the $7^{\text {th }}$ day of treatment.

The average indicators of fibrinogen in the comparison group were as follows: $4.6 \pm 0.1 \mathrm{~g} / \mathrm{l}$ initially, with a decrease to $2.8 \pm 0.1 \mathrm{~g} / \mathrm{l}$ on the $14^{\text {th }}$ day with moderate severity; $4.8 \pm 0.1 \mathrm{~g} / \mathrm{l}$ initially with a decrease to $3.3 \pm 0.1 \mathrm{~g} / \mathrm{l}$ in a severe cohort; and from $5.4 \pm 0.3 \mathrm{~g} / \mathrm{l}$ of the initial with a decrease to $3.8 \pm 0.1 \mathrm{~g} / \mathrm{l}$ in a cohort of an extremely severe form of the disease. The average indicators of fibrinogen in the main group of patients were as follows: $4.7 \pm 0.2 \mathrm{~g} / \mathrm{l}$ initially, with a decrease to $2.4 \pm 0.2 \mathrm{~g} / \mathrm{l}$ on the $14^{\text {th }}$ day with moderate severity; $5.1 \pm 0.2 \mathrm{~g} / \mathrm{l}$ initially with a decrease to $2.7 \pm 0.1 \mathrm{~g} / \mathrm{l}$ in a severe cohort; and from $5.6 \pm 0.2 \mathrm{~g} / \mathrm{l}$ of the initial one with a decrease to $3.1 \pm 0.1 \mathrm{~g} / \mathrm{l}$ in a cohort of an extremely severe form of the disease (Figure 3).

Analyzing the comparative dynamics of average fibrinogen values (Figure 3) showed an intergroup statistically significant difference $(t=2.12-3.18 ; \mathrm{P}<0.05)$ and better indicators in the main group of patients at all stages of therapy. So, as can be seen from Figure 3, already on the $3^{\text {rd }}$ day after the start of therapy with anticoagulants and antiplatelet agents, the average blood fibrinogen in the comparison group was decreased from $4.9 \pm 0.2 \mathrm{~g} / \mathrm{l}$ to $4.6 \pm 0.1 \mathrm{~g} / \mathrm{l}$, while in the main group it was reduced from $5.1 \pm 0.2 \mathrm{~g} / \mathrm{l}$ to $4.2 \pm 0.1 \mathrm{~g} / \mathrm{l}(\mathrm{t}=2.12 ; \mathrm{P}<$ 0.05). Subsequently, this trend was maintained and the indicator was achieved by 14 days $(3.3 \pm 0.1 \mathrm{~g} / \mathrm{l}$ in the comparison group and $2.7 \pm 0.2 \mathrm{~g} / \mathrm{l}$ in the main study group; $\mathrm{t}=2.92 ; \mathrm{P}<0.05)$.

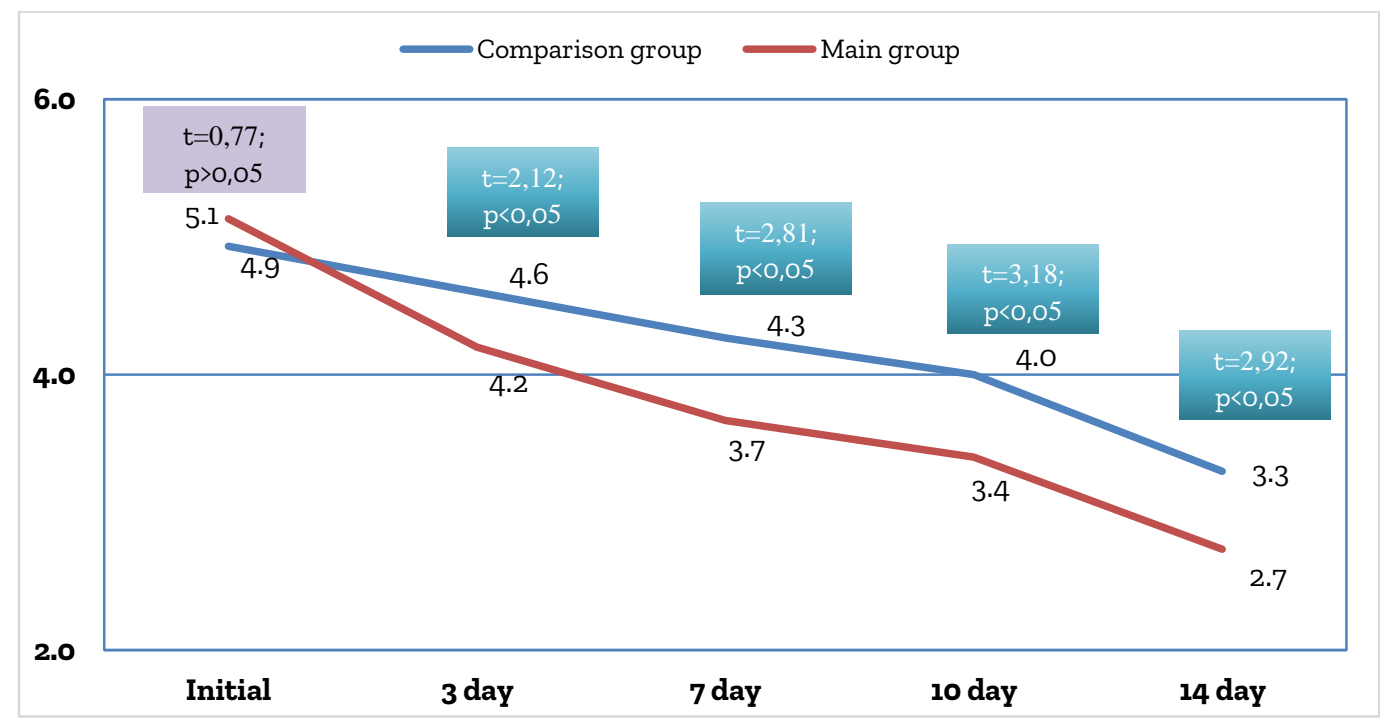

Figure 3. Comparative dynamics of fibrinogen index (g/l).

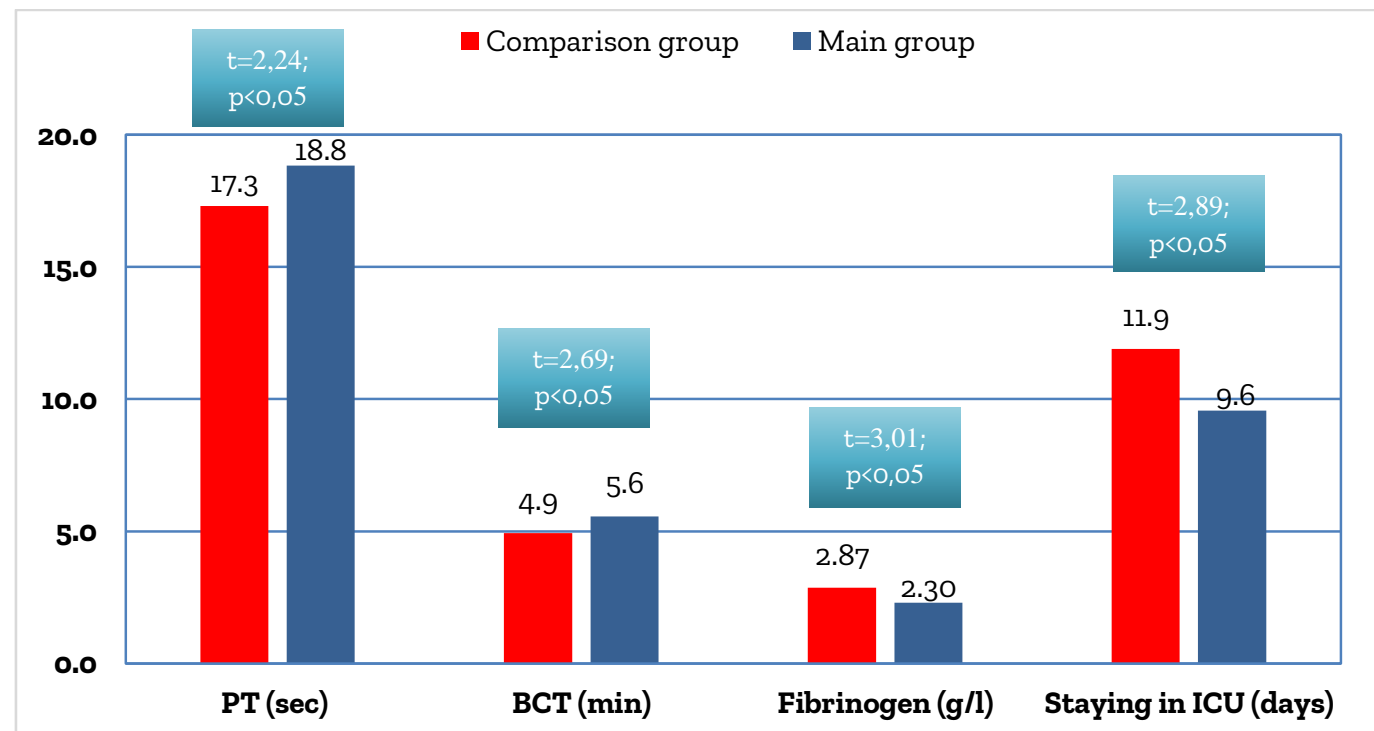

Figure 4. Average indicators of coagulation activity at the time of transfer from the intensive care unit (ICU). 


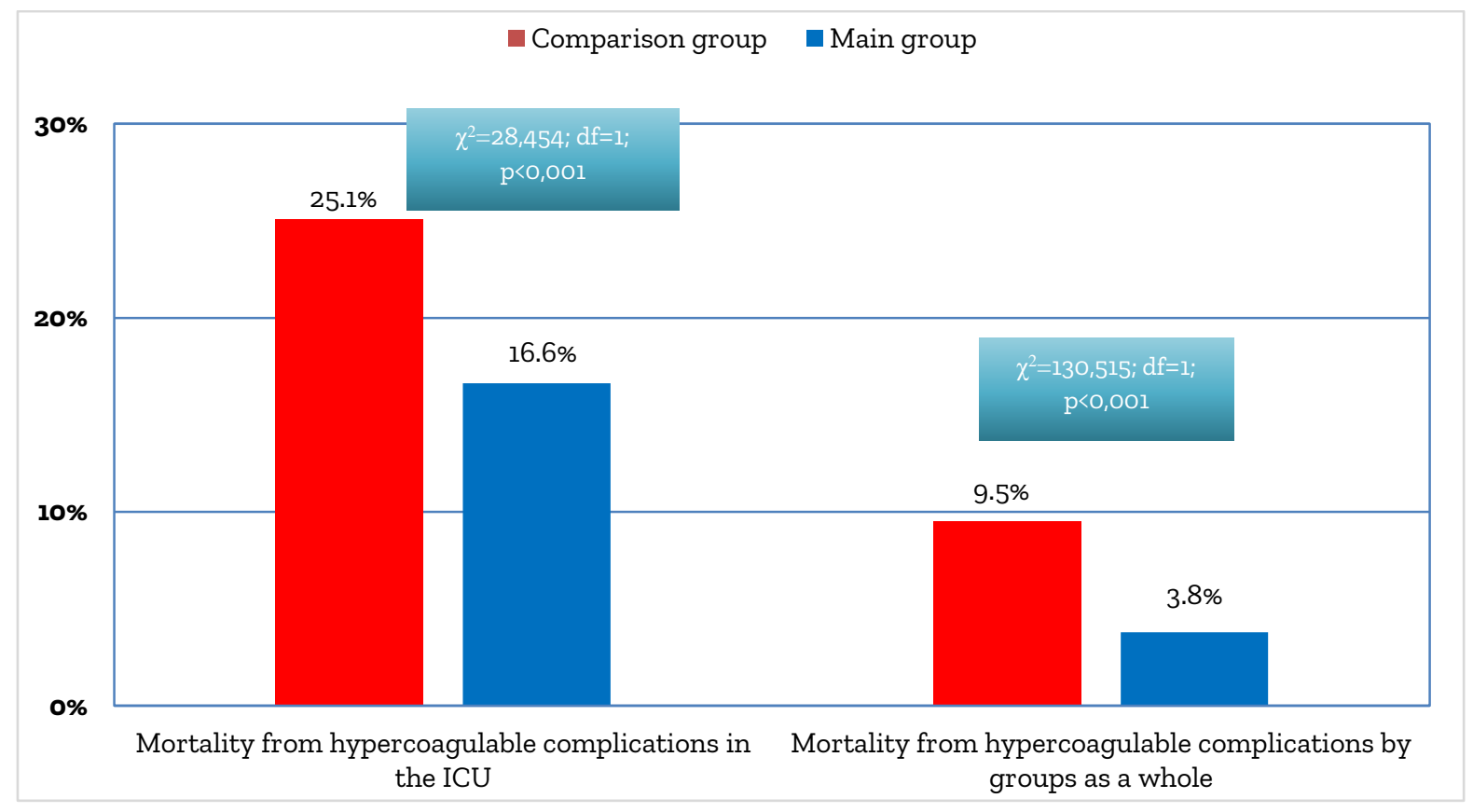

Figure 5. Mortality rates from hypercoagulable complications in the ICU.

Comparative analysis (Figure 4) showed that at the time of transfer from the ICU, the average prothrombin time (PT) was $18.8 \pm 0.5 \mathrm{sec}$ in the main group's patients and $17.3 \pm 0.5 \mathrm{sec}$ in the comparison group $(\mathrm{t}=2.24 ; \mathrm{P}<0.05)$. A statistically significant difference was also obtained in relation to the clotting time (CT) (5.6 $\pm 0.2 \mathrm{~min}$. versus $4.9 \pm 0.2 \mathrm{~min} ., \mathrm{P}<0.05)$ and fibrinogen $(2.3 \pm 0.1 \mathrm{~g} / \mathrm{l}$ versus $2.9 \pm 0.1 \mathrm{~g} / \mathrm{l}, \mathrm{P}<0.05)$. The average duration of ICU stay was $9.6 \pm 0.5$ bed-days in the main group and $11.9 \pm 0.6$ bed-days in the comparison group $(\mathrm{t}=2.89 ; \mathrm{P}<0.05)$. In the comparison group, coagulopathy resulting in death was noted in $9.5 \%$ of cases. In the main group, these indicators were lower with a statistically significant difference (3.8\%) (Figure 5).

\section{CONCLUSION}

According to the developed recommendations, when an increased risk of thrombus formation is detected, enoxaparin ( $0.8 \mathrm{mg}$ s/c 2 times a day) should be combined with acetylsalicylic acid (75-150 mg/day) and Clopidogrel (150-300 mg/day). In cases of failure to achieve the target levels of PT and CT, anticoagulant therapy should be carried out with the introduction of Heparin $\mathrm{i} / \mathrm{v} 1000 \mathrm{U} / \mathrm{h}$. In the absence of factors of increased risk of thrombus formation, the effective dose of enoxaparin is set as $160 \mathrm{mg}$ (0.8 ml) per day, divided into 2 doses. In cases of failure to reach the target levels of PT and CT one day after the start of anticoagulant therapy, it is necessary to manage the patient as if there is a high risk of thrombus formation.

The introduction of optimized tactics for anticoagulant therapy in patients with severe and extremely severe COVID-19 course made it possible to accelerate the dynamics of prothrombin time improvement from $12.0 \pm 0.4$ to $13.6 \pm 0.3$ seconds by the $3^{\text {rd }}$ day of intensive therapy ( $\left.P<0.05\right)$, and by day 10 from $14.7 \pm 0.4$ to $16.2 \pm 0.3$ $\sec (\mathrm{P}<0.05), \mathrm{BCT}$ from $3.1 \pm 0.1$ to $3.3 \pm 0.1 \mathrm{~min}(\mathrm{P}<0.05)$ and from $3.7 \pm 0.1$ to $4.5 \pm 0.1 \mathrm{~min}$, respectively, and fibrinogen from $4.6 \pm 0.2$ to $4.2 \pm 0.1 \mathrm{~g} / \mathrm{l}(\mathrm{P}<0.05)$ and from $4.0 \pm 0.1$ to $3.4 \pm 0.1 \mathrm{~g} / \mathrm{l}$, which ensured a decrease in the likelihood of developing fatal thromboembolic complications in ICU conditions from 25.1\% to $16.6 \%$ ( $<<0.001$ ) and in general for groups from $9.5 \%$ to $3.8 \%(\mathrm{P}<0.001)$.

\section{DECLARATIONS}

\section{Acknowledgements}

This work was supported by "Republican Specialized Scientific and Practical Medical Center for Surgery named after academician V.Vakhidov" and "Center for the development of professional qualifications of medical workers", Tashkent, Uzbekistan

\section{Competing interests}

The authors declare that they have no competing interests. 


\section{REFERENCES}

1. Tang N, Li D, Wang X, Sun Z. Abnormal coagulation parameters are associated with poor prognosis in patients with novel coronavirus pneumonia. Journal of thrombosis and haemostasis. 2020 Apr; 18(4):844-7. DOI: https://doi.org/10.1111/jth.14768

2. Al-Ani F, Chehade S, Lazo-Langner A. Thrombosis risk associated with COVID-19 infection. A scoping review. Thrombosis research. 2020 Aug 1; 192:152-60. DOI: https://doi.org/10.1016/j.thromres.2020.05.039

3. Mehra MR, Desai SS, Kuy S, Henry TD, Patel AN. Cardiovascular disease, drug therapy, and mortality in Covid-19. New England Journal of Medicine. 2020 Jun 18; 382(25):e102. DOI: https://doi.org/10.1056/NEJMoa2007621

4. Luo WR, Yu H, Gou JZ, Li XX, Sun Y, Li JX, He JX, Liu L. Histopathologic findings in the explant lungs of a patient with COVID-19 treated with bilateral Orthotopic lung transplant. Transplantation. 2020 Nov 1; 104(11):e329-31. DOI: https://doi.org/10.1097/TP.0000000000003412

5. Labò N, Ohnuki H, Tosato G. Vasculopathy and coagulopathy associated with SARS-CoV-2 infection. Cells. 2020 Jul; 9(7):1583. DOI: https://doi.org/10.3390/cells9o71583

6. Driggin E, Madhavan MV, Bikdeli B, Chuich T, Laracy J, Biondi-Zoccai G, et al. Cardiovascular considerations for patients, health care workers, and health systems during the COVID-19 pandemic. Journal of the American College of Cardiology. 2020 May 12; 75(18):2352-2371. DOI: https://doi.org/10.1016/j.jacc.2020.03.031

7. Pfortmueller CA, Spinetti T, Urman RD, Luedi MM, Schefold JC. COVID-19 associated acute respiratory distress syndrome (CARDS): current knowledge on pathophysiology and ICU treatment-a narrative review. Best Practice \& Research Clinical Anaesthesiology. 2020 Dec 17. https://doi.org/10.1016/j.bpa.2020.12.011 